\title{
Tendências pedagógicas na produção do conhecimento em educação em enfermagem do estado de São Paulo
}

\author{
Learning trends in the production of knowledge in nursing education in the state of São Paulo \\ Tendencias pedagógicas en la producción del conocimiento en educación de \\ enfermería en el estado de São Paulo
}

\section{Bruna Pedroso Canever', Marta Lenise do Prado", Vânia Marli Schubert Backes", Mariana Cabral Schveitzer"II \\ 'Universidade Federal de Santa Catarina, Centro de Ciências da Saúde, Departamento de Enfermagem, Programa de Pós-Graduação em Enfermagem (Doutoranda). Florianópolis-SC, Brasil. \\ "Universidade Federal de Santa Catarina, Centro de Ciências da Saúde, Departamento de Enfermagem, \\ Programa de Pós-Graduação em Enfermagem. Florianópolis-SC, Brasil. \\ I' Universidade de São Paulo, Escola de Enfermagem, Programa de Pós-Graduação em Enfermagem (Doutoranda). São Paulo-SP, Brasil.}

Submissão: 12-09-2012 Aprovação: 22-11-2013

\section{RESUMO}

Pesquisa qualitativa, do tipo descritiva, exploratório-analítica, em base documental. O objetivo foi caracterizar e analisar as tendências pedagógicas encontradas na produção de artigos científicos relacionados à temática Educação em Enfermagem, capturadas a partir da publicação dos pesquisadores dos Grupos de Pesquisa em Educação em Enfermagem do Estado de São Paulo de 2004 a 2010. Foram identificadas as seguintes tendências pedagógicas: Tradicional, Renovada, Tecnicista, Libertadora e a Crítico-Social dos Conteúdos. Foram analisados 131 estudos, sendo que $46,56 \%$ estão pautados em tendências centralmente marcadas por preocupações políticas e sociais. Percebeu-se um movimento intenso em busca de transformação da Educação em Enfermagem dentro dos Grupos de Pesquisa. A grande concentração de estudos embasados em tendências libertadoras ou com a ambição de adotar tais posturas, revela um fator positivo dos Grupos de Pesquisa em Educação em Enfermagem.

Descritores: Educação em Enfermagem; Pesquisa em Enfermagem; Pesquisa em Educação em Enfermagem.

\section{ABSTRACT}

This is a qualitative, descriptive, exploratory and analytical research, with documentary basis. The objective was to characterize and analyze teaching trends found in scientific articles related to the topic Education in Nursing, captured from the publication of the researchers of Research Groups in Nursing Education of the State of São Paulo from 2004 to 2010. We identified the following teaching trends: Traditional, Renewed, Tecnicist, Liberating and Critical Social-Contents. We analyzed 131 studies, of which $46.56 \%$ are graded in trends centrally marked by political and social concerns. He noticed a movement in search of intense transformation of Nursing Education within Research Groups. A large concentration of studies grounded in liberating tendencies or the ambition to adopt such postures, reveals a positive factor of Research Groups in Nursing Education.

Key words: Nursing Education; Nursing Research; Research in Nursing Education.

\section{RESUMEN}

Investigación cualitativa, descriptiva, exploratoria y analítica, con base documental. El objetivo fue caracterizar y analizar las tendencias de enseñanza que se encuentran en artículos científicos relacionados con el tema de Educación en Enfermería, en publicación de investigadores de los Grupos de Investigación en Educación en Enfermería del Estado de São Paulo, desde 2004 hasta 2010. Hemos identificado las siguientes tendencias de la enseñanza: Tradicional, Renovada, Tecnicist, de Liberación y de Contenidos Crítico-Sociales. Se analizaron 131 estudios, de los cuales 46,56\% se califican en las tendencias marcadas en el centro de las preocupaciones políticas y sociales. Se dio cuenta de un movimiento en busca de una intensa transformación de la Educación en Enfermería en los Grupos de Investigación. Una gran concentración de estudios basadas en las tendencias liberadoras o la ambición de adoptar las posturas, revela un factor positivo de los Grupos de Investigación en Educación en Enfermería.

Palabras clave: Educación en Enfermería; Investigación en Enfermería; Investigación en la Educación de Enfermería.

\section{AUTOR CORRESPONDENTEＢruna Pedroso Canever E-mail: brunacanever@gmail.com}




\section{INTRODUÇÃO}

Com a instituição das Diretrizes Curriculares Nacionais para o curso de graduação em Enfermagem em 2001, novas indicações foram estabelecidas sobre o processo educacional, preconizando que a formação do futuro enfermeiro deve ser generalista, crítico-reflexiva, aperfeiçoando habilidades e competências a partir do encontro entre a teoria e a prática, refletindo em um profissional preparado para trabalhar com base nos princípios do Sistema Único de Saúde (SUS) e preocupado com a transformação da realidade social em que está inserido ${ }^{(1)}$

A partir dessas diretrizes, desencadeou-se um movimento de reestruturação curricular nos cursos das Instituições de Ensino Superior (IES), requerendo assim a implantação de Projetos Políticos Pedagógicos (PPP) que viabilizem uma relação de interdependência entre currículo e prática pedagógica emergindo um novo paradigma na formação acadêmica ${ }^{(2)}$.

$\mathrm{Na}$ contemporaneidade, almeja-se um processo educativo que se estabeleça em um contexto social, a partir de uma prática pedagógica desenvolvida por meio de relações dialógicas que proporcionem a reflexão sobre o processo de ensino e o empoderamento a partir dos conhecimentos construídos pelos educandos e educadores ${ }^{(3)}$.

No campo da Educação em Enfermagem, a produção científica incentiva a incorporação, a socialização e a produção de conhecimentos por meio de um processo multidimensional de perspectivas e prioridades, construídas nas relações dos diferentes saberes dos sujeitos sociais que participam ativamente desse processo. Esses fatores são fundamentais para a formação do profissional Enfermeiro, sendo que este processo não pode ser apenas teórico, mas requer a reflexão sobre a realidade social e a possibilidade de discussões acerca do significado na formação do profissional. A base desta formação requer preparo teórico-prático, ancorado em uma postura pedagógica ${ }^{(4)}$.

As opções pedagógicas adotadas no processo educativo mostram as ideologias e os objetivos do contexto, trazendo consequências discerníveis sobre a conduta individual e coletiva, sobre o comportamento da sociedade em seu conjunto, como também na formação dos profissionais da área ${ }^{(5)}$. Os processos educativos se desenvolvem tendo como base uma determinada tendência pedagógica, sendo assim, quando se aprofundam os conhecimentos acerca destes processos, é possível ter clareza de qual caminho, quais objetivos e finalidades querem se alcançar na formação dos profissionais de Enfermagem $^{(6)}$.

As tendências pedagógicas podem ser classificadas em: Tradicional, Renovada, Tecnicista, Libertadora e a Crítico-Social dos Conteúdos. Em cada uma delas é possível identificar características que as distinguem e revelam um modo de pensar a educação e o processo de aprendizagem que delas decorre $^{(7)}$. A seguir apresentam-se as principais características das tendências pedagógicas.

Na tendência Tradicional, a questão central é aprender a reproduzir, sendo que a postura do educador é autoritária, aquele que detém o conhecimento, a relação entre educador-educando é vertical. Assim, o educando é considerado um sujeito passivo que apenas recebe o conhecimento, e a escola tem a responsabilidade por uma formação moral, intelectual e de esforços. Os conteúdos são passados de uma forma lógica, rigorosa e coerente, como forma de memorização utiliza-se a repetição de exercícios. A aprendizagem ocorre de forma repetitiva e mecânica e a avaliação é um processo superficial, em que o comportamento e a memória do aprendiz são objetos de estudo ${ }^{(7)}$.

Nas tendências Renovada e Tecnicista, destaca-se como questão principal do ensino o aprender a aprender e o aprender a fazer. A postura do professor ainda é autoritária, e a relação entre professor (instrutor) e aprendiz é apenas técnica existindo assim a consciência do limite grupal. O aprendiz é o sujeito que necessita adquirir apenas habilidades técnicas. A postura da escola enquadra-se em um processo ativo de construção de habilidades e técnicas, ou seja, uma preparação para o mundo do trabalho. Sendo assim, o ensino é baseado em aprender e executar as técnicas sendo que decorar cada ação ainda é essencial. Os pressupostos da aprendizagem baseiam-se no aprendizado como uma questão de modificação do desempenho, modelagem e o processo avaliativo ocorre por meio de provas objetivas, sendo que a mesma está diretamente ligada aos objetivos estabelecidos e ocorre ao término do processo com a finalidade de constatar se os aprendizes adquiriram as habilidades desejadas ${ }^{(7)}$.

Nas tendências Libertadora e Crítico-Social dos Conteúdos, a questão central é aprender viver a junto - aprender a ser, o professor deixa de ser autoritário e é considerado facilitador ou mediador do processo educativo a relação entre educador e educando é horizontal e o aprendiz é considerado um sujeito crítico, reflexivo e autônomo. A escola prepara os aprendizes para o mundo adulto e suas contradições e os conteúdos são desenvolvidos em torno de problemas reais, em que todos participam da construção do conhecimento por meio de grupos de discussões e o processo ensino-aprendizagem ocorre por meio da compreensão, reflexão, crítica-síntese. A avaliação é um processo contínuo, que ocorre desde a primeira interação entre educador e aprendiz ${ }^{(7)}$.

Acredita-se que, para a consolidação de uma formação profissional preparada para atuar no SUS, na busca da interdisciplinaridade, é condição sine qua non a adoção de tendências pedagógicas que contribuam para uma formação crítica e criativa do futuro profissional, a partir de inovações dentro dos currículos, nos PPPs e com estratégias diferenciadas de ensino, visando formar futuros enfermeiros habilitados para atuar na realidade social em prol do bem-estar da população(8).

Diante da necessidade de adoção de tendências pedagógicas que contribuam na formação para o SUS, faz-se necessário estudar acerca das diferentes tendências pedagógicas encontradas na produção cientifica em Educação em Enfermagem. Neste sentido, este estudo objetiva analisar as tendências pedagógicas da produção científica dos Grupos de Pesquisa em Educação em Enfermagem (GPEE) originada, especificamente, no Estado de São Paulo.

A escolha pela especificidade do Estado de São Paulo é justificada pelo mesmo constituir-se em um importante polo acadêmico do Brasil, com considerável impacto na produção 
científica, sendo o Estado com maior número de Grupos de Pesquisa em Educação em Enfermagem e publicações na área ${ }^{(9)}$. Sendo assim, a partir dessa análise, será possível compreender o que e como esta produção científica contribui na orientação do processo ensino-aprendizagem na formação dos futuros profissionais de enfermagem.

\section{MÉTODO}

Trata-se de uma pesquisa do tipo descritiva, exploratório-analítica, em base documental, de natureza qualitativa. Os dados foram obtidos por meio do Censo CNPq 2008, disponível online, a partir da análise da produção científica dos pesquisadores pertencentes aos Grupos de Pesquisa em Educação em Enfermagem do estado de São Paulo. O período de coleta dos dados ocorreu no mês de janeiro de 2011.

Os dados foram capturados e organizados por ano de publicação em livrarias a partir do gerenciador bibliográfico EndNote ${ }^{\circledast}$. A partir da captação dos estudos no formato completo, realizou-se a leitura na íntegra, a identificação da natureza dos estudos e categoria temática Educação, Enfermagem e Saúde, englobando os estudos a partir das similaridades dos temas mais publicados a saber: Formação Profissional, Competências, Tecnologia Educacional, Educação Permanente em Saúde, Processo Ensino-Aprendizagem, Perfil dos Programas de Pós-Graduação, Ensino na Assistência, Educação Popular, Interdisciplinaridade, Experiência dos Estudantes, Prática Pedagógica.

A análise dos dados ocorreu a partir da proposta operativa em relação à Análise Qualitativa(10). Para elucidar as tendências pedagógicas utilizadas pelos autores dos artigos científicos, foram usados recortes textuais com o número do estudo sequencial e seu respectivo ano de publicação, mantendo em anonimato a identidade dos autores.

Por tratar-se de uma pesquisa documental, este estudo não foi submetido ao Comitê de Ética com Seres Humanos. Destaca-se que os preceitos éticos que integram a resolução CNS 196/96 foram mantidos.

\section{RESULTADOS E DISCUSSÃO}

Os dados do Censo 2008 do CNPq mostram que o estado de São Paulo possui 12 Grupos de Pesquisa em Educação em Enfermagem. A partir da análise da produção científica dos 94 pesquisadores pertencentes a estes grupos, constatou-se um total de 557 artigos científicos, sendo que, deste montante, 131 estudos estavam relacionados com a temática educação publicados em periódicos com qualificação A1, A2, B1 e B2 conforme Qualis/CAPES 2010, disponíveis on-line na íntegra, no período de 2004 a 2010.

Quanto à natureza dos estudos, 83 são pesquisas, dos quais 59 caracterizam-se como pesquisas qualitativas, 22 são pesquisas quantitativas e 02 são pesquisas quali-quantitativas; 24 são reflexões teóricas, 13 são revisão de literatura e 11 são relatos de experiência.

No que se refere à temática Educação, Enfermagem e Saúde, os temas mais abordados podem ser evidenciados na tabela 1.
Tabela 1 - Temas da produção de artigos científicos dos Grupos de Pesquisa em Educação em Enfermagem do Estado de São Paulo.

\begin{tabular}{lcc}
\hline TEMAS & $\mathbf{N}$ & $\mathbf{\%}$ \\
\hline Processo Ensino-Aprendizagem & 30 & 22,90 \\
Perfil e Trajetória & 26 & 19,84 \\
Formação Profissional & 24 & 18,32 \\
Tecnologia Educacional & 13 & 9,92 \\
Educação Permanente em Saúde & 12 & 9,16 \\
Competências & 11 & 8,39 \\
Ensino na Assistência & 07 & 5,34 \\
Prática pedagógica & 03 & 2,29 \\
Experiência dos estudantes & 03 & 2,29 \\
Educação Popular & 01 & 0,76 \\
Interdisciplinaridade & 01 & 0,76 \\
\hline Total & $\mathbf{1 3 1}$ & $\mathbf{1 0 0}$ \\
\hline
\end{tabular}

Fonte: Censo 2008 CNPq e Plataforma Lattes/CNPq, 2011.

A partir da leitura na íntegra dos 131 estudos, foram extraídos recortes textuais para melhor elucidar a conformação das tendências pedagógicas dos autores dos estudos dos artigos analisados. Destaca-se que em muitos textos pode-se observar a presença de uma tendência pedagógica tradicional ou tecnicista, mas que evidenciava um forte movimento em busca de transformação para uma tendência libertadora, sendo assim, foram feitos os seguintes agrupamentos: Tendência Tradicional, Transição da Tendência Tecnicista para a Libertadora, Tendência Renovada e Tendência Tecnicista, Transição da Tendência Tradicional para a Libertadora, Tendência Libertadora e Crítico-Social Dos Conteúdos.

\section{TENDÊNCIA TRADICIONAL}

Representando a menor parte dos estudos encontrados nesta busca, a tendência Tradicional está presente em 08 estudos, o que significa $6,10 \%$ de toda produção dos Grupos de Pesquisa. A essência destes textos aborda a maneira que os conteúdos são transmitidos, de professores para estudantes, como evidenciado nos recortes textuais abaixo:

Nos currículos dos cursos da área da saúde, entre eles o de enfermagem [...], ainda é possível visualizar a relação assimétrica entre as disciplinas do tipo fechada, com conteúdos delimitados em relação vertical, sendo a pré-requisitação um recurso continuamente utilizado como forma de viabilizar a interdisciplinaridade. (Estudo 02, ano 2010)

Observamos, de modo geral, que a avaliação dessa temática é tratada de modo tradicional, por meio de provas escritas, apresentações orais e trabalhos como foi relacionado por $44 \%$ das escolas pesquisadas. (Estudo 26, ano 2005)

A prática pedagógica amparada em pressupostos da tendência Tradicional possui uma visão essencialista imutável do 
ser humano. O processo educativo nesta lógica orienta-se a partir de um "modelo ideal" já existente e que não leva em consideração o contexto que está inserido.

Nota-se ainda que alguns educadores permanecem presos às formas tradicionais de ensino em sala de aula, afastados da realidade social, numa relação unilateral, acreditando ser detentor do saber. Considera-se que a dicotomia entre a teoria e a prática aliados ao autoritarismo e ao processo pedagógico distantes de uma reflexão crítica dos docentes sejam fatores que precisam ser revistos para o alcance de melhorias exitosas na formação do futuro profissional ${ }^{(11)}$.

\section{DA TENDÊNCIA TECNICISTA PARA A LIBERTADORA}

Movimentos da tendência Libertadora também podem ser identificados em estudos tecnicistas, como ocorreu com 13 $(9,92 \%)$ dos textos integrantes desta pesquisa. Percebe-se que, mesmo os textos sendo, em sua essência, focados na tendência tecnicista, os autores evidenciam a limitação desta prática educativa e a necessidade de um novo olhar pedagógico:

Compete ao coordenador (docente) articular conceitos e experiências, valores humanistas, voltados para o desenvolvimento de competências e o aprender a aprender. A dimensão tecnológica deve ir além das competências técnicas específicas, abrangendo a reflexão sobre os padrões éticos, sociais, culturais, econômicos e educacionais decorrentes da disseminação e utilização da tecnologia. (Estudo 55, ano 2009)

Os fragmentos dos textos acima ainda que focados na pedagogia Tecnicista já apresentam indícios de uma transformação necessária do ponto de vista pedagógico. Uma transformação pedagógica no sentido de ultrapassar a prática centrada apenas na habilidade técnica. Neste sentido, a relação dialógica entre educando e educador contribui com o desenvolvimento de cada um na sua individualidade, respeitando a cultura e os saberes distintos. O conhecimento é construído nesta relação, alcançando a humanização e reconhecimento um no outro, gerando o processo de ação e reflexão e potencializando as oportunidades de adquirir novos conhecimentos.

Diante do exposto, é fundamental destacar que é no desenvolvimento de uma prática dialógica e reflexiva que o saber dos educandos se concretiza e é compartilhado entre pares. A práxis da reflexão torna-se importante para a mudança da prática diária e, neste âmbito, o docente enfermeiro necessita ter domínio das suas ações bem como a responsabilidade em manter segura a integridade e curiosidade no processo de aprendizagem dos educandos ${ }^{(12)}$.

\section{TENDÊNCIA RENOVADA E TENDÊNCIA TECNICISTA}

Com o movimento das tendências pedagógicas, os conteúdos escolares e os professores deixaram de ser tratados como núcleos da educação e os educandos iniciam seu processo de libertação educativa, porém ainda limitado. Estes movimentos foram encontrados em 15 (11,45\%) dos 131 estudos, que nos trazem detalhes destas tendências, os quais se podem perceber no recorte do texto abaixo:

O procedimento, produto da aprendizagem, ocorre pela capacidade de organizar ações para alcançar uma meta. Nesta perspectiva, a aquisição de conhecimento procedimental consiste em transpor a condição de saber dizer para a condição de saber fazer. (Estudo 54, ano 2008)

Percebe-se neste recorte que a formação está relacionada com atividades de natureza técnica. O cuidado administrado pelos profissionais não raro é realizado de forma mecânica, norteado por tarefas, seguindo rigidamente normas e prescrições. As relações pessoais, por sua vez, quase sempre se apresentam frágeis. A habilidade técnica é priorizada em detrimento da relação estabelecida entre as pessoas. A tendência Tecnicista afasta o profissional/educando da realidade social enfocando apenas a visão biologicista e tecnicista do processo saúde-doença ${ }^{(13)}$.

\section{TRANSIÇÃO DA TENDÊNCIA TRADICIONAL PARA LIBERTADORA}

Neste grupo foram evidenciados 34 (25,95\%) estudos que inicialmente focalizaram e trabalharam com a tendência tradicional, que apresentavam aspectos rígidos e autoritários, específicos desta tendência pedagógica. Todavia, também percebemos nesses textos que os autores reconheciam fragilidades desta tendência e refletem sobre a necessidade de iniciativas e atividades características da tendência libertadora, como se apresenta a seguir:

O desafio da mudança da prática avaliativa no ensino-aprendizagem, encontra-se no pressuposto de que o professor se libere do uso autoritário da avaliação que o sistema lhe faculta e autoriza, empenhando-se em construir uma nova prática, adotando o papel de educador, deslocando o centro de sua ação de fiscalizar/medir/julgar para propiciar a aprendizagem, tendo em vista o compromisso com a aprendizagem de todos os estudantes. (Estudo 18, ano 2007)

A educação a distância visa suprir a necessidade de mão de obra qualificada, e deve ser adotada como uma nova forma de educar e não como uma 'roupagem' para educação tradicional, apresentando técnicas inovadoras, como autonomia crítica e processos mediados pela comunicação síncrona e assíncrona. (Estudo 64, ano 2007)

É possível observar que, tanto os educadores, como os educandos ainda sentem dificuldades em assumir uma postura libertária. Este fato pode-se justificar pelo contexto histórico fortemente marcado por um sistema educativo tradicional. A educação bancária presente ainda na atualidade, caracterizada pelo ato de depositar conhecimentos nos educandos ainda impera com fortes influências na sociedade.

Ainda existe o conflito de superação das formas tradicionais de ensino, vivido por educadores e educandos. Ao 
mesmo tempo em que desenvolvem processos tradicionais de ensino, reconhecem que, para o avanço na formação do profissional enfermeiro, é fundamental que todos os envolvidos no processo educativo consigam transcender o papel histórico e cultural da tendência tradicional. Também reconhecem a necessidade de estabelecer novas relações entre educador e educando permeadas pelo diálogo e generosidade, facilitando dessa forma o processo de aprendizagem do educando.

No estudo, ficou evidente a necessidade de uma opção consciente e reflexiva dos docentes em relação à inserção das novas tecnologias no processo ensino-aprendizagem em enfermagem, construindo uma concepção de informática compatível com a dimensão humana da prática profissional da enfermagem, baseada no diálogo, na relação face a face, onde o professor assume uma postura de facilitador desse processo, compreendendo as funções da informática nas dimensões do ensino, pesquisa, assistência e gerenciamento de enfermagem. (Estudo 63, ano 2004)

Em decorrência do momento do ensino que vivenciamos atualmente ser dinâmico e influenciado pelo passado do processo de aprendizagem, destaca-se que as escolas de enfermagem precisam buscar formas diferenciadas por meio de seus currículos para formar futuros profissionais competentes e comprometidos com a sociedade e as mudanças que se aplicam a mesma, com vistas de uma reflexão crítica e reflexiva sobre a sua repercussão na prática profissional(14).

\section{TENDÊNCIA LIBERTADORA E CRÍTICO-SOCIAL DOS CONTEÚDOS}

Do total de estudos analisados, 61 (46,56\%) estão pautados em tendências centralmente marcadas por preocupações políticas e sociais. Podem-se verificar estudos pautados nestas tendências que trabalham com a formação do futuro profissional de enfermagem contribuindo dessa forma com uma formação preocupada com a realidade social que visa à transformação, como se observa nos recortes textuais a seguir:

A formação adota a perspectiva da contextualização e da escuta das necessidades de saúde também assegura ao aluno a capacidade de problematizar e de descobrir as soluções criativas e cooperativas para os problemas reais, permitindo a construção do saber e autonomia, com a intervenção do profissional de saúde na reorientação do modelo assistencial. (Estudo 01, ano 2004)

A formação deve ser pautada no contexto da realidade e não centrada em conteúdos descontextualizados dos aspectos sócio, político, econômico e cultural em que a sociedade se organiza. A formação do enfermeiro, em sintonia com os pressupostos e diretrizes do SUS, possibilita vislumbrar uma educação freiriana, que por ser emancipatória e transformadora da realidade permite, ao individuo, responder aos desafios do mundo contemporâneo sendo protagonista da sua própria história. (Estudo 23, ano 2009)
Assim, a formação profissional pretendida para o egresso dos cursos de enfermagem é mais aberta e dialógica e ao mesmo tempo crítica; mais flexível e ao mesmo tempo mais rigorosa; solidamente alicerçada em conhecimentos e principalmente, fundamentada na ética, voltada para o desenvolvimento do raciocínio, da autonomia, da criatividade, da comunicação e da capacidade de identificar problemas e buscar alternativas para superá-los. (Estudo 15, ano 2007).

Estes recortes fortalecem a importância da educação ser vista como prática da liberdade. Para que o processo ensino-aprendizagem ocorra pautado em uma tendência libertadora e crítico-social dos conteúdos é necessário que educador e educando desenvolvam a sensibilidade do ato de aprender juntos mesmo possuindo experiências/saberes diferentes.

Neste movimento, os educandos precisam ter liberdade despertando a sua criatividade, sendo este um fator essencial para o processo educativo. Além disto, a tendência libertadora torna-se incompatível com uma pedagogia que de maneira consciente ou mistificada, tem sido prática de dominação. Uma cultura tecida com a trama da dominação, por mais generosos que sejam os propósitos dos seus educadores, é barreira cerrada às possibilidades educacionais dos que se situam nas subculturas dos proletários e marginais ${ }^{(15)}$.

Os educadores não apenas instruem, mas estimulam o aluno a tomar decisões, fazer observações, perceber relações e trabalhar com hipóteses. Dessa forma, o professor facilita ao estudante que incremente o seu poder (empowerment), ou seja, conducentes a aquisição de poder técnico (saber) e político para atuar em prol da sociedade. (Estudo 10, ano 2006)

Um dos eixos principais da prática freireana fundamenta-se na (re)educação do educador. A formação profissional do educador e seu compromisso com a sociedade necessitam ser um processo constante e permanente imerso em um contexto social, que é condicionador, mas não dependente dele. É necessário a existência de uma estreita relação entre o pensar e a agir dando maior visibilidade à autonomia pedagógica dos educadores com vistas à transformação do contexto social.

Para o educador-educando, dialógico, problematizador, o conteúdo programático da educação não é uma doação ou uma imposição - um conjunto de informes a ser depositado nos educandos, mas a revolução organizada, sistematizada e acrescentada ao povo, daqueles elementos que este Ihe entregou de forma desestruturada ${ }^{(15)}$.

Os estudos que abordaram como ocorre o processo ensino-aprendizagem dentro de uma tendência emancipatória, ressaltam a importância do educador como facilitador e estimulador no processo educativo. Além disso, destacam como elementos-chave neste contexto o diálogo, a amorosidade, a empatia e o respeito para com os educandos. A curiosidade epistemológica, como inquietação ao desvelamento do novo, é parte essencial do processo educacional ${ }^{(16)}$. 
Os recortes textuais abaixo elucidam o que foi dito anteriormente:

É preciso estar aberto à diversidade e as diferenças individuais e culturais, valores e crenças dos sujeitos envolvidos no processo ensino-aprendizagem, valorizando-se os vínculos afetivos e as efetivas amorosidade, possibilitando, dessa forma, o diálogo consensual e a construção do conhecimento. (Estudo 28, ano 2010)

A aplicação do modelo de avaliação emancipatória com os enfermeiros da Unidade de Terapia Intensiva Coronariana de um Hospital de Ensino [...] proporcionou a reflexão, a compreensão e a transformação das atividades educativas de forma libertadora (Estudo 46, ano 2007)

Essa educação, por sua vez, não deve ser vista apressadamente como um programa centrado na transmissão pura e simplesmente, por meio do ato de depositar, transferir e transmitir valores e conhecimentos, visando à modelagem de formas de pensar, sentir e agir. Deve ser concebida, a partir da perspectiva dialógica de Paulo Freire, como o usuário do serviço ser reconhecido como sujeito portador de um saber que pode ser base para uma prática emancipatória de ressignificação do processo saúde-doença-cuidado. (Estudo 22, ano 2010)

No que diz respeito à postura dos educadores dentro do processo educativo, a produção científica dos Grupos de Pesquisa em Educação em Enfermagem aponta para uma prática docente crítica e reflexiva, em que o educador busque adquirir princípios éticos na relação educador/educando no intuito de alcançar uma realidade justa e solidária.

Tanto o curso presencial quanto o curso a distância de qualidade possuem os mesmos ingredientes. Ambos dependem de educadores maduros (intelectual e emocionalmente), entusiasmados e que saibam motivar e dialogar. Depende, também, da curiosidade e da motivação dos alunos, o que facilita e estimula as melhores qualidades do professor [...]. (Estudo 125, ano 2008)

A opção pedagógica para o site foi trabalhar na perspectiva que considera o aluno como construtor do seu conhecimento, no qual o professor deve ser orientador/facilitador do processo educativo, com base nas propostas emancipadoras e libertadoras de Paulo Freire. (Estudo 62, ano 2007)

A implementação desses recursos no ensino depende de uma concepção de educação que valoriza o diálogo e considera 'o aluno como um sujeito que constrói seu caminho rumo ao conhecimento', sendo o professor aquele que auxilia nesta construção. (Estudo 60, ano 2007)

Também foi possível averiguar em muitos textos, a importância do trabalho em grupo, sendo o mesmo considerado como uma mola propulsora na interação e desenvolvimento entre os pares. Como é possível observar nos recortes textuais abaixo:

O papel do coordenador de grupos nesse contexto é o de atuar como um facilitador que fortalece o grupo, propiciando o elo coesivo - a sinergia - que se constitui no elemento essencial, na força impulsionadora do desenvolvimento grupal. (Estudo 30, ano 2007)

O trabalho grupal deve ser fundamentado na comunicação contínua entre os pares, integrando o ambiente interno e externo e transformando a administração auto centrada, formal e fechada em administração que contemple o caráter da interdependência; sendo dinâmica, participativa, integradora e flexível, e ainda, aberta, democrática e cooperativa, na qual os indivíduos possuem senso de autonomia sem perder a concentração na meta coletiva. (Estudo 95, ano 2004)

Outro aspecto evidenciado na produção científica nesta tendência foi o papel do educando no processo ensino-aprendizagem. Para essa tendência é fundamental que o mesmo participe como sujeito ativo e curioso na construção do seu conhecimento, sendo imprescindível o desenvolvimento da autonomia e o respeito ético a este princípio, como pode ser percebido nos extratos textuais a seguir:

A autonomia do aluno nos processos de aprender a fazer, a conviver, e a ser, torna-se um desafio colocado aos professores de enfermagem. A autonomia caminha de modo inseparável da liberdade e da responsabilidade, e não está dissociada do convívio social, em comunidade; é um processo simultaneamente individual e coletivo, micro e macro-orientado, e se desenvolve por meio da participação ativa do sujeito - neste caso, o aluno. (Estudo 91, ano 2010)

A intenção dos programas educativos de gerarem habilidades para uma tomada de decisão contextualizada e plena nos seus determinantes biopsicológicos é complexa e, do ponto de vista pedagógico, requer uma proposta de ensino capaz de promover o aprendizado de forma autônoma e reflexiva; com respeito aos conhecimentos e experiências prévias; permeado pelo contato com a realidade com o meio ambiente, com as outras pessoas. (Estudo 86, ano 2010)

Para que ocorra a verdadeira transformação no ato educativo, os educadores necessitam induzir a percepção e curiosidade dos educandos em relação ao contexto no qual cada um está imerso, mostrando que o processo educativo ocorre para além da sala de aula, através da liberdade e da reflexão coletiva e individual perante a sociedade. Sendo assim, a sala de aula deve ser entendida como um momento inicial do processo educativo(16).

\section{CONSIDERAÇÕES FINAIS}

A partir da análise dos 131 artigos científicos produzidos pelos Grupos de Pesquisa em Educação em Enfermagem, 
percebe-se um movimento intenso em busca de transformação da Educação em Enfermagem. Identifica-se o desejo do rompimento com o modelo cartesiano do processo ensino-aprendizagem. A grande concentração de textos embasados em tendências libertadoras, ou com a ambição em adotá-las, revela um fator positivo na postura destes Grupos de Pesquisa.

Neste sentido, destaca-se que na formação dos profissionais de Enfermagem é imprescindível a presença do pensamento crítico-reflexivo, problematizando os pressupostos e fundamentos desta formação, reafirmando dessa forma os compromissos que consideram básicos para a cidadania, onde a educação assume o papel de mediadora de uma prática social.

Para que a Enfermagem como ciência transcenda de forma efetiva para posturas pedagógicas libertadoras é importante que os Grupos de Pesquisa em Educação em Enfermagem considerados importantes disseminadores desse conhecimento, desenvolvam e incentivem trabalhos que fomentem o debate, demonstrem experiências pedagógicas exitosas, desvelem os resultados da formação a partir de processos pedagógicos diferenciados, contribuindo com a transformação que a formação em Enfermagem requer para fazer frente aos novos desafios do mundo contemporâneo.

\section{REFERÊNCIAS}

1. Conselho Nacional de Educação. Câmara de Educação Superior (Brasil). Resolução CNE/CES nº. 3, de 07 de nov de 2001. Institui Diretrizes Curriculares Nacionais do Curso de Graduação em Enfermagem [resolução na internet]. Diário Oficial da União 09 nov 2001 [acesso em 12 set 2012];Seção 1. Disponível em: http://portal.mec.gov. br/cne/arquivos/pdf/CES03.pdf.

2. Pinto JBT, Pepe AM. A formação do enfermeiro: contradições e desafios à prática pedagógica. Rev Latino-Am Enferm. 2007;15(1):1-8.

3. Reibnitz KS, Prado ML. Inovação e educação em enfermagem. Florianópolis: Cidade Futura; 2006.

4. Saupe R. Ação e reflexão na formação do enfermeiro através dos tempos. In: Saupe R. Educação em enfermagem: da realidade construída á possibilidade em construção. Florianópolis: UFSC; 1998.

5. Bordenave JED. Alguns fatores pedagógicos. In: Ministério da Saúde. Secretaria de Modernização Administrativa e Recursos Humanos. Capacitação pedagógica para instrutor/supervisor área da saúde. Brasília: Ministério da Saúde; 1989.

6. Nóbrega-Therrien SM, Guerreiro MGS, Moreira TMM, Almeida MI. Projeto Político Pedagógico: concepção, construção e avaliação na Enfermagem. Rev Esc Enferm USP 2010;44(3):679-686.

7. Ministério da Educação e Cultura. Parâmetros Curriculares Nacionais: introdução aos parâmetros curriculares nacionais. Brasília, DF: Ministérios da Educação e Cultura; 1997. p. 30-33
8. Costa RKS, Miranda FAN. Sistema Único de Saúde e da família na formação acadêmica do enfermeiro. Rev Bras Enferm. 2009;62(2):18-26.

9. Backes VMS, Prado ML, Lino ML, Ferraz F, Reibnitz, KS, Canever BP. Grupos de pesquisa de educação em enfermagem do Brasil. Rev Esc Enferm USP 2012;46(2):436-42.

10. Minayo MCS. O desafio do conhecimento: pesquisa qualitativa em saúde. 8. ed. São Paulo: HUCITEC; 2010.

11. Silva MG, Fernandes JD, Teixeira GAS, Silva RMO. Processo de formação da(o) enfermeira(o) na contemporaneidade: desafios e perspectivas. Texto \& Contexto Enferm. 2010;19(1):176-184.

12. Rodrigues MTP, Mendes Sobrinho JAC. Enfermeiro professor: um diálogo com a formação pedagógica. Rev Bras Enferm. 2007;60(4):456-459.

13. Nietsche EA. As teorias da educação e o ensino da enfermagem no Brasil. In: Saupe R, organizadora. Educação em enfermagem: da realidade construída à possibilidade em construção. Florianópolis: UFSC; 1998.

14. Vasconcelos CMCB, Backes VMS, Gue JM. Avaliação no ensino de graduação em enfermagem na América Latina: uma revisão integrativa. Enferm Glob 2011;55(23):118-139.

15. Freire P. Pedagogia do oprimido. Rio de Janeiro: PAZ E TERRA; 2005.

16. Freire $P$. Pedagogia da autonomia: saberes necessários à prática educativa. São Paulo: PAZ E TERRA; 2011. 